\title{
Cómo definir los nombres de instrumentos musicales. Propuesta lexicográfica*
}

JACINTO GONZÁLEZ COBAS

Universidad Autónoma de Madrid

\section{INTRODUCCIÓN}

En la actualidad se insiste con frecuencia en la necesidad de confeccionar los diccionarios a partir de una serie de principios a los que se llega tras un complejo proceso de reflexión y planificación que ha de presidir la consecución de todo proyecto lexicográfico. ${ }^{1}$ Es la forma de garantizar, o al menos favorecer, que estas obras se lleven a cabo con métodos claros de trabajo que reviertan en una sistematización tanto conceptual como formal. Ello facilita sin duda la labor de quienes se enfrentan a la ardua tarea de elaborar y actualizar los diccionarios, así como la consulta de sus potenciales usuarios, que reconocen en aquellos la existencia de cierta nómina de procedimientos con que interpretarlos y utilizarlos de manera óptima.

Las decisiones que hay que tomar en esa etapa de planificación son de muy variado tipo, y del acierto de las mismas depende en gran medida el éxito en los resultados. Entre ellas ocupan un lugar de extraordinaria importancia las relacionadas con el establecimiento de modelos de definición aplicables a grupos homogéneos de palabras. Para ello es absolutamente necesario parcelar el léxico de la lengua en cuestión, si bien no siempre es fácil elegir el método más adecuado para hacerlo.

En una publicación anterior (González Cobas, 2010) me decantaba por aprovechar los importantes avances alcanzados por la Lingüística en los últimos tiempos precisamente para seccionar el vocabulario de un idioma, lo cual permite incidir, por otro lado, en la conexión directa que ha de establecerse entre aquella y la Lexicografía. ${ }^{2}$ Resultado de esa manera de proceder es la delimitación de un conjunto de vocablos (el

\footnotetext{
* Una versión preliminar de este trabajo se presentó en el XXVI Congreso Internacional de Lingüística y Filología Románicas (Valencia, 6-11 de septiembre de 2010). Quiero expresar mi agradecimiento a Elena de Miguel, Ana Serradilla y Santiago U. Sánchez Jiménez por las sugerencias y comentarios formulados a propósito de este trabajo, que se enmarca en dos proyectos de investigación (FFI2009-10817 y FFI2009-12191), financiados por el Ministerio de Ciencia e Innovación y dirigidos por Inés FernándezOrdóñez y Elena de Miguel respectivamente.

${ }^{1}$ Véanse, entre otros, Ahumada Lara (1989), Béjoint y Thoiron (2002), Geeraerts (2003), Kiefer y Sterkenburg (2003), Soler i Bou (2003), DeCesaris y Bernal (2005), Del Moral (2006), Pascual y García Pérez (2007), Porto Dapena (2007) y González Cobas (2009, 2010).

${ }^{2}$ Consúltese también Apresjan (2008).

JACINTO GONZÁLEZ COBAS, «Cómo definir los nombres de instrumentos musicales. Propuesta lexicográfica», Revista de Lexicografía, XVII (2011), pp. 65-82. ISSN: 1134-4539, e-ISSN: 2603-667. DOI: https://doi.org/10.17979/rlex.2011.17.0.3783
} 
de los nombres de instrumentos musicales), que manifiesta similar comportamiento lingüístico y que conforma un grupo muy fácil de reconocer por los hablantes. ${ }^{3}$

La intención última de esta investigación es ofrecer a los lectores un patrón definitorio para los citados sustantivos, como una manera a partir de la cual avanzar hacia una mayor sistematización en la elaboración de las definiciones. Dicho patrón gravita sobre dos puntales: la elección de los datos que han de figurar en las definiciones y las construcciones lingüísticas con que codificarlos. Desde luego otros modelos son posibles si se varían los criterios elegidos para confeccionarlos, pero más importante que optar por unos u otros principios es la aplicación regular y ordenada de los mismos.

\section{CORPUS Y RASGOS DE DEFINICIÓN}

Como señala Batiukova (2009: 492), «Hoy en día resulta impensable la recogida y preparación de datos para un diccionario sin la ayuda de corpus informatizados: estos contienen datos reales de la lengua y constituyen por tanto una base objetiva para su estudio, a diferencia de métodos de análisis más subjetivos (como los basados en la intuición del lingüista)». Con seguridad esto motiva que la lexicografía más reciente considere fundamental acudir a este tipo de fuentes para extraer información relacionada sobre todo con la selección del lemario, la separación de acepciones, la frecuencia de uso de determinada palabra, su dispersión geográfica o para detectar combinaciones estables de vocablos, entre otros aspectos. ${ }^{4}$

En González Cobas (2010) hago alusión a la posibilidad de utilizar los corpus, además de para lo señalado supra, para indagar los rasgos semánticos caracterizadores de un grupo específico de palabras, determinar cuáles de entre ellos han de estar necesariamente en sus respectivas definiciones (en virtud de su recurrencia), así como averiguar los aspectos más destacados de su naturaleza referencial.

La consulta en el CREA de un nutrido elenco de nombres de instrumentos musicales me lleva a concluir que los usuarios de la lengua emplean, cuando actualizan estos sustantivos y hacen mención de los mismos en un contexto específico, un número de rasgos semánticos bastante elevado. Es habitual encontrarlos, por ejemplo, en pasajes de texto en que se alude al modo de funcionamiento de los instrumentos designados (ejemplos 1 y 2), a su ámbito de uso (ejemplos 3 y 4), a la familia a la que pertenecen (ejemplos 5 y 6), a su origen (ejemplos 7 y 8), al material de su fabricación (ejemplos 9 y 10), a su descripción completa (ejemplos 11 y 12), a sus elementos compositivos (ejemplos 13 y 14), al sonido que producen (ejemplos 15 y 16), al ámbito geográfico en que se utilizan (ejemplos 17 y 18), a sus antecesores o sucesores (ejemplos 19 y 20), al colectivo que los toca (ejemplos 21 y 22), a si se trata de instrumentos antiguos o de reciente creación (ejemplos 23 y 24) o a establecer comparaciones con otros instrumen-

\footnotetext{
${ }^{3}$ Acerca de la conducta gramatical de los sustantivos que designan instrumentos, véase González Cobas (2010).

4 Véanse Atkins (2008), Cowie (2008), Church y Hanks (2008), Fillmore (2008), Hanks (2008), Kilgarriff (2008), Kilgarriff, Rychly, Smrž y Tugwell (2008), Stock (2008) y Batiukova (2009).
} 
tos utilizando los más conocidos como punto de referencia para caracterizar otros menos populares (ejemplos 25 y 26):

(1) Ella cantaba y bailaba y yo, con estos dos dedos libres, la acompañaba con un rasgueo al requinto (Luis Landero, Juegos de la edad tardía, 1989).

(2) El rabel es un instrumento parecido al violín, de sólo tres cuerdas, que se toca apoyándolo en las rodillas y frotando sus cuerdas con un arco (Revista Musical Chilena, 07/2000).

(3) Al revisar la documentación de que disponemos, vemos que en la Cabrera existió, años atrás, un instrumento pastoril llamado "la gaita de la Cabrera", del que no hemos oído hablar en el terreno (Domingo Pliego, 100 Excursiones por la Sierra de Madrid, Tomo I, 1992).

(4) Ante tal opción no cabe escrúpulo academicista alguno: en México la guitarra constituye ante todo el instrumento popular por excelencia y la música de Revueltas se enraiza en zonas afines, de modo por igual entrañable y evidente (Proceso, 08/12/1996: "Encarnación").

(5) La música india era principalmente vocal. Con las cuerdas vocales se expresaban las melodías; pero aun en el caso de tocarse en algún instrumento de viento como una flauta, éste no era sino sustituto de la voz (Fernando Ortiz, La música afrocubana, 1975).

(6) Estamos hablando del salterio, instrumento de cuerda con la caja de resonancia de forma trapezoidal y que produce sonido al percutir sus cuerdas con un par de martillos de madera o con uñetas (Quinto Sol, n' 19, 2000: "El salterio del grupo Arpegio").

(7) El tambor llamador sostiene un figurado rítmico fijo, mientras el mayor realiza variaciones e improvisaciones. Estos tambores son claramente de origen africano (Helio Orovio, Música por el Caribe, 1990).

(8) Curiosamente, a veces incorporaban un banjo -instrumento de origen africano que reaparecería en la música negra y rural norteamericana- quitándole sus múltiples cuerdas para emplearlo como percutiente (Tony Évora, Orígenes de la música cubana. Los amores de las cuerdas y el tambor, 1997).

(9) Las quitiplas se fabrican con pedazos de bambú (Daniel Piquet, La cultura afrovenezolana, 1982).

(10) Además, el quinteto de chirimías (instrumento de viento hecho de madera a modo de clarinete) "Miguel Arrózpide" interpretó algunas melodías durante la apertura de la celebración en el claustro (Diario de Navarra, 07/01/2001: "Música sacra").

(11) Guamo o Fotuto. Instrumento indocubano, llamado también guamo. Consiste en un caracol marino, grande, en forma de tubo, al que se le ha roto el extremo de la espiral, para soplar por él, produciendo sonidos roncos de gran volumen (Anónimo, Récords y datos hispanoamericanos, 1988).

(12) Un conjunto breve, todo él femenino salvo dos intérpretes, vestido con túnicas azules, desarrolló sus bailes característicos. El denominado la guedra (nombre, a la vez, de una suerte de derbuka, instrumento de percusión formado por una piel de cabra sujeta a una vasija de barro cocido) constituye todo un ritual (El Pais, 01/10/1984: "Festival de Otoño"). 
(13) De estos instrumentos, en la España renacentista el más importante fue la vihuela, versión española de seis cuerdas del laúd nórdico, y ambos descendientes de instrumentos árabes (Jas Reuter, La música popular de México, 1980).

(14) El conjunto michoacano que interpreta sones se conoce como "conjunto de arpa grande", por ser su instrumento característico el arpa de más de 30 cuerdas, generalmente de 35, con amplia caja de resonancia que sirve a uno de los músicos de tambor (Jas Reuter, La música popular de México, 1980).

(15) Recuerdo el tono de su voz: tenía la monotonía de la dulzaina, la sequedad de sus notas, el chirriante susurro de sus falsetes. Y, sobre todo, su toque de alerta (Mercedes Salisachs, La gangrena, 1975).

(16) En Trujillo bailan en honor a San Benito, cuya danza tiene cabida al son de un tambor y de un curioso instrumento llamado "flauta chimbanguelera" el cual es alargado como una caña, contiene un poco de agua, se toca como el clarinete, es decir, no lateralmente como la flauta común, y produce un sonido monótono (estos son datos orales del citado ingeniero Antonio Bello Caballero) (Francisco Tamayo, El hombre frente a la naturaleza, 1993).

(17) Erké. Instrumento aerófono incaico, utilizado por los indios en Perú, Bolivia y en el norte de Argentina (Anónimo, Récords y datos latinoamericanos, 1988).

(18) Es posible que el rabel se haya conocido en toda América, como lo demuestra la existencia del rabel panameño y la rebeca brasileña, pero el instrumento con las características antes descritas sólo tiene vigencia en Chile, especialmente en la zona central (Revista musical chilena, 07/2000).

(19) Citamos sólo una anécdota de las narradas por el cronista Motolinía para ilustrar la musicalidad del indio: cierto soldado de Cortés que en Tlaxcala pasaba sus ratos de ocio tocando el rabel (antecesor del violín) le dio unas pocas lecciones a un indígena; a los pocos días, éste había construido su instrumento y había superado la destreza del maestro en su ejecución (Jas Reuter, La música popular de México, 1980).

(20) Los nahuas de los valles de Tlaxcala y Puebla acompañan casi todas sus celebraciones religiosas (católicas) con música interpretada por el llamado "conjunto azteca", que consta de chirimía (antecesor renacentista del oboe, con penetrante sonido nasal), huéhuetl y tambor redoblante, tocados el primero con baquetas de extremos acojinados y el segundo con palillos de madera (Jas Reuter, La música popular de México, 1980).

(21) En general las tocan [las maracas] los cantantes, hombres o mujeres (Daniel Piquet, La cultura afrovenezolana, 1982).

(22) Otro instrumento usado por los juglares fue la vihuela, un violín que normalmente se tocaba con el arco o también con la pluma (San Juan de la Cruz, $\mathrm{n}^{\circ}$ 31-32, 01-02/2003: "Francisco de Yepes: un juglar a lo divino I").

(23) Como en años anteriores, la jornada tiene un contenido de exhibición y de fiesta folklórica, dirigida a potenciar y conservar el uso de estos antiguos instrumentos, que son la gaita y la dulzaina (El País, 15/05/1980: “Concentración de gaiteros españoles en La Rioja").

(24) Choca realmente escuchar un concierto como el famoso "Emperador" de Beethoven tocado por un fortepiano y por un conjunto de instrumentos de la época 
[principios del siglo XIX] (ABC Cultural, 27/12/1996: "Beethoven: "Concierto número 5 Emperador. Fantasía para piano, coro y orquesta").

(25) Una orquesta de contradanza se componía normalmente de dos o tres violines, dos clarinetes en Do, un contrabajo, un cornetín (que solía llevar el canto principal), un trombón de pistones, un figle (instrumento de viento parecido a la trompeta pero de sonoridad grave), timbales o pailas de barriga redonda y cerrada, y un güiro (Tony Évora, Orígenes de la música cubana. Los amores de las cuerdas y el tambor, 1997).

(26) El rabel es un instrumento parecido al violín, de sólo tres cuerdas, que se toca apoyándolo en las rodillas y frotando sus cuerdas con un arco (Revista Musical Chilena, 07/2000).

Si se realizan búsquedas en el citado corpus de sustantivos que designan otras clases de instrumentos (como los de medida, por citar un caso concreto), se constata con facilidad que el anterior catálogo de rasgos se ve reducido considerablemente. Tanto es así que, si bien hay secuencias en que se alude al modo de funcionamiento (ejemplos $27 \mathrm{y}$ 28) o ámbito temático de aplicación de los objetos denotados por tales sustantivos (ejemplos 29 y 30), lo cierto es que la mayoría de las veces la función o finalidad de uso es la gran protagonista (ejemplos 31,32 y 33 ): ${ }^{5}$

(27) Le tomó el pulso. Le sujetó el termómetro en la axila, calva como la de un niño. Todo estaba bien (José Donoso, Donde van a morir los elefantes, 1995).

(28) "El equipo es como un espejo que permite observar lo que está sucediendo dentro del organismo", dice Claudia Londoño, sicóloga experta en el manejo del estrés y el dolor. En otras palabras, este aparato [el biofeedback] mide estas funciones como lo haría un termómetro debajo del brazo con la temperatura (Revista Semana, 13-19/11/2000: "No más estrés").

(29) Allí hay un reloj del tiempo universal, catálogos de estrellas brillantes, aparatos meteorológicos: termómetro, hidrómetro, barómetro, etcétera (Julieta Fierro, Los mundos cercanos, 1997).

(30) Como es lógico, todos los trabajos relativos a la implantación del sistema de cuadrículas han de efectuarse mediante los aparatos de medición topográfica (nivel, teodolito, mira, salones, cinta métrica, etc.), para trazar líneas rectas perpendiculares unas a otras, a la distancia convenida (Víctor M. Fernández Martínez, Teoría y método de la arqueología, 1990).

(31) También se disponía de un altímetro (no recuerda el nombre), para determinar la altura del aparato (La Prensa, 24-11-2000).

(32) El registro del cubano será revisado porque el pie del atleta podría haber tocado la plancha de apoyo en el momento del salto y, sobre todo, por la presencia constante de una persona delante del anemómetro que marca la velocidad del viento, mientras duró el salto (La Vanguardia, 2-8-95).

(33) En tanto, en el Puerto Barranqueras del Chaco, el hidrómetro marcó también 7,37 metros, con lo cual faltan sólo 30 centímetros para que el gran muelle de hormigón que custodia el lugar quede sumergido (Diario Hoy, 10-2-97).

\footnotetext{
${ }^{5}$ Recojo aquí casuística incluida en González Cobas (2010).
} 
No extrañan estas diferencias en el empleo que los hablantes hacen de unos y otros sustantivos si se tiene en cuenta que para catalogar una entidad como instrumento (y nombrarla lingüísticamente como tal) esta ha de tener necesariamente una función. ${ }^{6}$ Los instrumentos musicales no constituyen excepciones a esta premisa, a pesar de que, en contraposición a otros instrumentos, la finalidad de uso no basta para caracterizarlos, pues todos ellos persiguen una misma meta: producir música. Esta circunstancia obliga a definir los nombres de instrumentos musicales por medio de rasgos adicionales al de la función si se desea evitar confusiones en la identificación de los referentes designados por tales sustantivos. Dicho de otro modo: la función es un rasgo necesario pero insuficiente para describir semánticamente las palabras que nos ocupan. ${ }^{7}$

Del análisis de los datos extraídos — de los que se ha presentado una somera muestra en la página anterior - puede concluirse que los usuarios de la lengua se refieren con frecuencia, para aludir a los instrumentos musicales, a su modo de funcionamiento, ámbito de uso, origen, material de fabricación, descripción completa, a sus elementos compositivos, al sonido que producen, al ámbito geográfico en que se utilizan, a sus antecesores o sucesores, al colectivo que los toca, a su grado de antigüedad o a otros instrumentos con que compararlos. Dentro de esta lista figuran sin duda los elementos informativos que han de aparecer en sus definiciones, si bien es verdad que no todos ellos son necesarios para caracterizarlos semánticamente. ${ }^{8}$ Para distinguir unos y otros puede aplicarse el método contrastivo.

\section{EL MÉTODO CONTRASTIVO}

El análisis pormenorizado de los corpus puede complementarse al menos, como señalaba más arriba, con lo que he llamado método contrastivo. Este consiste en consultar los diccionarios de mayor prestigio de un idioma con el objetivo de comprobar cuáles son los rasgos semánticos empleados en estas obras para caracterizar determinado grupo de vocablos. En este sentido, el estudio conjunto de diversos diccionarios contribuye a obtener información relevante con la que confeccionar definiciones sistemáticas, por favorecer la adopción de una serie de medidas globales con que solucionar los complejos problemas que subyacen a la realización de un diccionario. En realidad, y tal y como señala Neubauer (1987), es una manera de utilizar los diccionarios como punto de partida para mejorar las técnicas lexicográficas. Se trata de una forma de actuación a

\footnotetext{
${ }^{6}$ Así se pone de manifiesto en las definiciones que, del lema instrumento, presentan tres de los diccionarios más representativos de nuestro idioma en su primera acepción: Diccionario de la lengua española de la RAE (DRAE en adelante): «Conjunto de diversas piezas combinadas adecuadamente para que sirva con determinado objeto en el ejercicio de las artes y oficios»; Diccionario del español actual de Seco, Andrés y Ramos $(D E A)$ : «Objeto fabricado, relativamente sencillo, que sirve para realizar con él un trabajo u otra operación»; Diccionario de uso del español de Moliner (DUE): «Objeto simple o formado de varias piezas, que se utiliza con las manos para ejecutar trabajos más delicados que los que se ejecutan con los útiles llamados herramientas, por ejemplo para efectuar una medición; como las pinzas, el compás o el barómetro». son (1986).

${ }^{7}$ Sobre el grado de especificidad de las definiciones, vid. Zgusta (1971) y Benson, Benson e Il${ }^{8} \mathrm{Vid}$. nota 10 .
} 
la que también Béjoint y Thoiron (2002) conceden gran importancia, por considerar que de las coincidencias y divergencias existentes en las definiciones de estas obras de consulta pueden extraerse datos significativos concretamente para elaborar un esquema básico de definición.

El examen del DRAE permite llegar en principio a varias conclusiones respecto de la tarea que nos ocupa:

El número total de rasgos semánticos utilizados para definir los nombres de instrumentos musicales en este diccionario es de 15, a saber: agente (ejemplo 34), ámbito geográfico de uso (ejemplos 35 y 36), comparación (ejemplos 37 y 38), cualidad (ejemplos 39 y 40), elementos compositivos (ejemplos 41 y 42), evolución (ejemplo 43), familia (ejemplos 44 y 45), forma (ejemplos 46 y 47), hipónimo (ejemplos 48 y 49), material (ejemplos 50 y 51), modo de funcionamiento (ejemplos 52 y 53), obsolescencia (ejemplos 54 y 55), origen (ejemplos 56 y 57), sonido resultante (ejemplos 58 y 59) y tamaño (ejemplos 60 y 61 ):

(34) Albogue. 1. m. Especie de flauta simple y rústica, o doble y de mayor complejidad de forma, generalmente de madera, caña o cuerno, propia de juglares $y$ pastores. U. m. en pl.

(35) Balalaica. 1. f. Instrumento musical parecido a la guitarra, pero con caja de forma triangular, de uso popular en Rusia.

(36) Bandoneón. 1. m. Variedad de acordeón, de forma hexagonal y escala cromática, muy popular en la Argentina.

(37) Churumbela. 1. f. Instrumento de viento, semejante a la chirimía.

(38) Violonchelo. 1. m. Instrumento musical de cuerda tocado con arco, más grande que la viola y más pequeño que el contrabajo y con un registro intermedio entre ambos. El intérprete, que está sentado, lo coloca entre sus piernas para tocarlo.

(39) Claviórgano. 1. m. Instrumento musical muy armonioso, que tiene cuerdas como un clave y flautas o cañones como un órgano.

(40) Zampoña. 1. f. Instrumento rústico, a modo de flauta, o compuesto de muchas flautas.

(41) Banyo. 1. m. Instrumento musical de cuerda que se compone de una caja de resonancia redonda cubierta por una piel tensada, un mástil largo con trastes y un número variable de cuerdas que se hacen sonar con los dedos o con púa.

(42) Clarinete. 1. m. Instrumento musical de viento, que se compone de una boquilla de lengüeta de caña, un tubo formado por varias piezas de madera dura, con agujeros que se tapan con los dedos o se cierran con llave, y un pabellón de clarin. Alcanza cerca de cuatro octavas y se usa mucho en orquestas y bandas militares.

(43) Maraca. 1. f. Instrumento musical suramericano, que consiste en una calabaza con granos de maíz o chinas en su interior, para acompañar el canto. Actualmente se hace también de metal o materiales plásticos. U. m. en pl.

(44) Bongó. 1. m. Instrumento musical de percusión, usado en algunos países del Caribe, que consiste en un tubo de madera cubierto en su extremo superior por un cuero de chivo bien tenso y descubierto en la parte inferior. 
Guitarra. 1. f. Instrumento musical de cuerda compuesto por una caja de resonancia en forma de ocho, un mástil largo con trastes, y cuerdas, generalmente seis, que se hacen sonar con los dedos.

(46) Arpa. 1. f. Instrumento musical de forma triangular, con cuerdas colocadas verticalmente y que se tocan con ambas manos.

(47) Nabla. 1. f. Instrumento musical muy antiguo, semejante a la lira, pero de marco rectangular y diez cuerdas de alambre, que se pulsaban con ambas manos.

(48) Cornetín. 1. m. Instrumento musical de metal, que tiene casi la misma extensión que el clarín. Los hay simples, de cilindro y de pistones, y estos últimos son los que se usan más generalmente, tanto en las bandas y charangas como en las orquestas.

(49) Trompa. 1. f. Instrumento musical de viento, que consiste en un tubo de latón enroscado circularmente y que va ensanchándose desde la boquilla al pabellón, donde se introduce más o menos la mano derecha para producir la diversidad de sonidos. También hay trompas en que la diversidad de sonidos se obtiene por medio de pistones.

(50) Castañuela. 1. f. Instrumento musical de percusión, compuesto de dos mitades cóncavas, hecho de madera u otro material. Por medio de un cordón que atraviesa las orejas del instrumento, se sujeta este al dedo pulgar o al de en medio y se repica con los demás dedos.

(51) Flauta. 1. f. Instrumento musical de viento, de madera u otro material, en forma de tubo con varios agujeros circulares que se tapan con los dedos o con llaves.

(52) Bandola ${ }^{1}$. 2. f. Ven. Instrumento musical de cuerda, de forma de pera y fondo chato, con cuatro cuerdas dobles que se hacen sonar con un plectro.

(53) Violín. 1. m. Instrumento musical de cuerda, el más pequeño y agudo entre los de su clase, que se compone de una caja de resonancia en forma de ocho, un mástil sin trastes y cuatro cuerdas que se hacen sonar con un arco.

(54) Albogón. 1. m. Instrumento musical antiguo de madera, de unos nueve decímetros de largo, a manera de flauta dulce o de pico, con siete agujeros para los dedos, el cual servía de bajo en los conciertos de flautas.

(55) Crótalo. 2. m. Instrumento musical de percusión usado antiguamente y semejante a la castañuela.

(56) Chachá. 1. m. Cuba. Instrumento musical de origen africano compuesto por una güira seca y hueca recubierta por una malla en cuyos hilos se insertan semillas que al mover la güira producen un sonido característico.

(57) Guaira. 3. f. Am. Cen. Instrumento de viento indígena compuesto de varias flautas.

(58) Lituo. 2. m. Instrumento de música militar que usaron los romanos, especie de trompeta de sonido agudo, de un metro aproximadamente de largo, con tubo recto y estrecho que a su extremidad se doblaba como un cayado.

(59) Serpentón. 1. m. Instrumento musical de viento, de tonos graves, que consiste en un tubo de madera delgada forrado de cuero, encorvado en forma de $\mathrm{S}$, más ancho por el pabellón que por la embocadura y con agujeros para los dedos o tapados con llaves.

(60) Armonio. 1. m. Órgano pequeño, con la forma exterior del piano, y al cual se da el aire por medio de un fuelle que se mueve con los pies. 
(61) Birimbao. 1. m. Instrumento musical pequeño, que consiste en una barrita de hierro en forma de herradura, que lleva en medio una lengüeta de acero que se hace vibrar con el índice de la mano derecha, teniendo con la izquierda el instrumento entre los dientes.

Si bien a menudo se reconoce un grado importante de homogeneidad en el tratamiento lexicográfico dado a estas palabras, lo cierto es que puede lograrse una mayor sistematización tanto en el catálogo de datos incluidos en las definiciones como en el vocabulario definidor. ${ }^{9}$

Si la comparación se extiende al $D E A$ y al $D U E$, se constata que no existe una coincidencia plena en el inventario de rasgos utilizados para definir cada uno de los lemas, y que ello no interfiere en ningún caso en la identificación de sus referentes. Ello solo puede significar que dentro de ese repertorio hay elementos semánticos prescindibles si lo que se trata es de caracterizar semánticamente una palabra con el menor número de datos evitando en todo momento la información no básica o enciclopédica. ${ }^{10}$ De hecho, si bien hay rasgos que pueden aparecer tanto en el $D R A E$ como en el $D E A$ y en el $D U E$ en la definición de uno u otro instrumento musical, no siempre están incluidos en las definiciones de una misma palabra, lo cual hace pensar que se trata de elementos semánticos irrelevantes para el propósito que se persigue. En los ejemplos 62 y 63 se ponen de manifiesto estas divergencias, en lo atingente a los rasgos forma y comparación respectivamente:

(62) Bandoneón. 1. m. Variedad de acordeón, de forma hexagonal y escala cromática, muy popular en la Argentina $(D R A E) / m$ Instrumento músico parecido al acordeón, pero de menor tamaño y de forma hexagonal, propio de las orquestas de tango $(D E A) / \mathrm{m}$. Pequeño acordeón con el que se tocan especialmente tangos (DUE).

(63) Bombardino. 1. m. Instrumento musical de viento, de metal, semejante al figle, pero con pistones o cilindros en vez de llaves, y que pertenece a la clase de bajos $(D R A E) / m 1$ Instrumento músico de viento, de metal, con pistones, de sección cónica y tubo plegado sobre sí mismo $(D E A) / \mathbf{m}$. Instrumento musical de viento, de sonido grave, con dos pistones $(D U E)$.

El análisis contrastivo propuesto también permite extraer conclusiones relevantes para determinar qué circunstancias o condiciones favorecen la inclusión de cierto tipo de datos en las definiciones. Una ojeada a cualquiera de los diccionarios manejados permite verificar, por citar un caso concreto, que no es demasiado habitual hacer mención del tipo de sonido que producen los instrumentos musicales designados por tales nombres, salvo en lemas como chachá o zambomba (ejemplos 64 y 65), que se caracterizan por emitir sonidos calificados de bruscos, monótonos o peculiares, lo cual en principio resulta bastante llamativo:

\footnotetext{
${ }^{9}$ Acerca de las ventajas e importancia de utilizar en los diccionarios un vocabulario definidor cerrado, consúltense Soler i Bou (2003) y González Cobas (2009).

${ }^{10} \mathrm{Vid}$. nota 10.
} 
(64) Chachá. ${ }^{11}$ 1. m. Cuba. Instrumento musical de origen africano compuesto por una güira seca y hueca recubierta por una malla en cuyos hilos se insertan semillas que al mover la güira producen un sonido característico (DRAE) / m. Cuba Instrumento musical que consiste en una güira hueca y seca cubierta de una malla en cuyos hilos se insertan semillas secas que, al chocar con la güira, producen un sonido característico (DUE).

(65) Zambomba. 1. f. Instrumento rústico musical, de barro cocido o de madera, hueco, abierto por un extremo y cerrado por el otro con una piel muy tirante, que tiene en el centro, bien sujeto, un carrizo a manera de mástil, el cual, frotado de arriba abajo y de abajo arriba con la mano humedecida, produce un sonido fuerte, ronco y monótono $(D R A E) / f \mathbf{1}$ Instrumento musical rústico constituido por un cilindro abierto por un extremo y cerrado por el otro con una piel tirante a la que va sujeto, a manera de mástil, un carrizo, el cual, frotado con la mano, produce un sonido ronco $(D E A)$ / f. Instrumento musical rudimentario formado por un cilindro de madera o metal (a veces, un bote vacío) u otro material, una de cuyas bases se tapa con un pergamino a cuyo centro se sujeta una caña; pasando la mano humedecida, oprimiendo con fuerza, por esa caña, vibra el pergamino y produce un sonido ronco; es un *juguete muy usado en los días de *Navidad (DUE).

Algo parecido ocurre con el rasgo comparación, que cobra importancia sobre todo en las definiciones de los lemas que refieren instrumentos extranjeros poco conocidos. Da la sensación de que, en bastantes ocasiones, los tres diccionarios manejados optan por establecer comparaciones con instrumentos musicales más populares entre los hablantes, con el objetivo de que estos últimos comprendan las principales características de esos instrumentos foráneos:

(66) Balalaica. 1. f. Instrumento musical parecido a la guitarra, pero con caja de forma triangular, de uso popular en Rusia $(D R A E) / f$ Instrumento músico popular ruso, de la familia de la guitarra, con caja triangular (DEA) / Instrumento musical ruso semejante a la guitarra, pero de caja triangular $(D U E)$.

(67) Tiorba. 1. f. Instrumento musical semejante al laúd, pero algo mayor, con dos mangos y con ocho cuerdas más para los bajos $(D R A E) / f$ Instrumento músico de la familia del laúd, con dos mangos, típico del siglo XVI $(D E A) / 1$ f. Antiguo instrumento musical semejante al laúd, pero más grande $(D U E)$.

\section{PROPUESTA DE MODELO DE DEFINICIÓN}

La aplicación del método contrastivo, en los términos descritos, permite concluir que, en las definiciones de los nombres de instrumentos musicales, la mención de los rasgos agente, evolución e hipónimo no es necesaria. Ello significa que, en mi propuesta de modelo definitorio para un diccionario de uso, prescindo de los elementos semánticos que acaban de ser citados. ${ }^{12}$ Esto no implica que los demás rasgos a que se ha

${ }^{11}$ Este lema no figura en el $D E A$.

${ }^{12}$ Es obvio que el prototipo cambiaría si este se destinase a un diccionario enciclopédico, en el que con toda seguridad se ampliaría el número de datos de las definiciones. Muy probablemente ocurriría lo contrario con un diccionario escolar o con un diccionario escrito para estudiantes extranjeros. 
aludido en estas páginas deban aparecer siempre en las definiciones de todos los lemas que designen este tipo de instrumentos, sino que en determinadas condiciones son relevantes y desempeñan un papel fundamental en la individualización de sus referentes, tal y como se explica en cada uno de los apartados que siguen, en los que se presentan definiciones que podrían constituir ejemplos provisionales de este modelo, que también incluye propuestas de fórmulas de codificación lingüística.

\section{1. Ámbito geográfico de uso}

Deberá aparecer cuando el instrumento denotado tenga un alcance espacial restringido, tal y como sucede con charango y balalaica. Sugiero la construcción usado en + locativo (u otras similares) para dar cuenta de este dato.

(68) Charango. m. Instrumento musical de cuerda, usado especialmente en la zona andina, parecido a una pequeña guitarra de cinco cuerdas dobles cuya caja de resonancia está hecha a veces con caparazón de armadillo.

(69) Balalaica. f. Instrumento musical de cuerda de uso popular en Rusia, parecido a la guitarra, pero con caja de forma triangular.

\subsection{Comparación}

Se incluirá en las definiciones de las palabras que aludan a instrumentos muy antiguos o de origen extranjero y poco conocidos, como el teponastle o el ukelele (ejemplos 70 y 71). También para definir lemas que mantengan una relación derivativa o de dependencia respecto de otros lemas (ejemplos 72 y 73). Eso sí, en el primer caso es muy importante que los nombres de instrumentos utilizados como término de la comparación formen parte, en la medida de lo posible, del acervo cognoscitivo de los hablantes.

Establecer en esta ocasión un medio de expresión sistemático resulta complicado, debido a que son muy diversos los criterios de comparación (forma, tamaño, etc.) que pueden aplicarse. No obstante, y si es posible, recomiendo utilizar la expresión pareci$d o$ a, a la que puede adjuntarse la conjunción adversativa pero siempre que resulte necesario introducir el elemento distinguidor respecto de otro instrumento musical.

(70) Teponastle. m. Instrumento musical indígena parecido al tambor pero de menor tamaño.

(71) Ukelele. m. Instrumento musical de origen hawaiano parecido a la guitarra pero de menor tamaño y con cuatro cuerdas.

(72) Claviórgano. m. Instrumento musical de viento y teclado, con cuerdas como el clave y tubos como el órgano, que produce un sonido muy armonioso.

(73) Contrabajón. m. Instrumento musical de viento que suena una octava más grave que el bajón.

\subsection{Elementos compositivos}

Puede ser conveniente insertar este rasgo sobre todo en las definiciones de algunos nombres de instrumentos pertenecientes a una misma familia y entre los cuales existe 
cierta semejanza desde un punto de vista denotativo, pero también algunas diferencias que interesa hacer explícitas. Planteo utilizar, como posibilidades de codificación lingüística, la conjunción adversativa pero seguida de la preposición con (en el caso de que sean los elementos compositivos los objetos de la comparación), o las construcciones formado por o compuesto por:

(74) Cornetín. m. Instrumento musical de viento metal, parecido a la corneta pero con pistones o llaves y de sonido similar al del clarín.

(75) Laúd. m. Instrumento musical de cuerda parecido a la bandurria, pero de caja más grande y sonido menos agudo.

(76) Armónica. f. Instrumento musical de viento formado por una serie de lengüetas fijas en una placa de metal y encerradas en una estructura de madera, que se toca soplando o aspirando.

(77) Violín. m. Instrumento musical de cuerda y arco compuesto por una caja de resonancia en forma de ocho, un mástil sin trastes y cuatro cuerdas.

\subsection{Familia}

La inclusión de este dato es muy importante por las repercusiones que tiene pertenecer a uno $\mathrm{u}$ otro grupo de instrumentos, en aspectos como el sonido o el modo de funcionamiento. Lo más sencillo es que este tipo de información figure al principio de las definiciones, restringiendo el alcance significativo de las mismas (ejemplos 78 y 79), ${ }^{13}$ aunque también es posible que se transmita en expresiones que hacen referencia, por citar un caso concreto, al número de cuerdas que posee determinado instrumento (ejemplo 80). Quedarán fuera de esta forma de actuación, como es lógico, los nombres cuyas definiciones se inicien con hiperónimos intermedios o no máximos, que en el caso que nos ocupa se trata de todos aquellos que no coinciden con la palabra instrumento (ejemplos 81 y 82).

(78) Contrabajo. m. Instrumento musical de cuerda y arco, parecido al violín pero de tamaño mucho mayor y de tono mucho más grave, que se toca apoyándolo en el suelo.

(79) Flauta. f. Instrumento musical de viento consistente en un tubo con orificios que se tapan y destapan para producir los distintos sonidos.

(80) Ukelele. m. Instrumento musical de origen hawaiano, parecido a la guitarra pero de menor tamaño y con cuatro cuerdas.

(81) Ajabeba. f. Flauta morisca.

(82) Adufe. m. Pandero morisco de forma cuadrada.

\subsection{Forma}

Se tendrá en cuenta si se trata de un rasgo distinguidor (esto es, cuando ayuda a diferenciar dos nombres de instrumentos próximos desde un punto de vista referencial), o

${ }^{13}$ En este sentido, patrones posibles de redacción serían Instrumento musical de cuerda (y arco), Instrumento musical de percusión, Instrumento musical de viento (madera/metal) o Instrumento musical de cuerda/viento y teclado. 
si constituye un elemento de comparación en las condiciones reseñadas anteriormente. Propongo dar cuenta de este dato mediante las expresiones de forma + adjetivo o en forma de + nombre:

(83) Balalaica. f. Instrumento musical de cuerda de uso popular en Rusia, parecido a la guitarra, pero con caja de forma triangular.

(84) Bandoneón. m. Instrumento musical de viento parecido al acordeón, pero de menor tamaño y de forma hexagonal, típico de la música de tango.

(85) Platillos. pl. Instrumento musical de percusión compuesto por dos piezas metálicas en forma de disco que se golpean una contra otra.

\subsection{Material}

Se precisará al menos con los instrumentos de viento, cuando constituye un factor claro de clasificación («instrumento de viento madera / metal»):

(86) Bombarda. f. Antiguo instrumento musical de viento madera, parecido a la chirimía, con lengüeta doble de caña.

(87) Figle. m. Instrumento musical de viento metal consistente en un tubo, doblado por la mitad, que va ensanchándose desde la boquilla hasta el pabellón y que está provisto de pistones.

\subsection{Modo de funcionamiento}

Puede ser interesante introducir este rasgo especialmente en las definiciones de instrumentos poco conocidos para la mayoría de los hablantes por una u otra razón, y/o con los que no se realiza ninguna comparación con instrumentos que compartan el modo de funcionamiento. Codificar este tipo de información es complicado, debido a que son diversos y un tanto heterogéneos los contenidos que pueden recogerse bajo la misma. Puede priorizarse, eso sí, el uso de la palabra tocar:

(88) Anemocordio. m. Antiguo instrumento musical, consistente en una caja sonora con seis u ocho cuerdas afinadas en el mismo tono, que se hacian vibrar exponiendo el instrumento a una corriente de aire.

(89) Calabazo. m. Instrumento musical de percusión que tiene como caja una calabaza de güiro ahuecado y que se toca golpeándolo con un palo pequeño, una varilla metálica o una baqueta.

\subsection{Obsolescencia}

Es importante precisar este dato, puesto que determina aspectos relevantes del objeto denotado por la palabra en cuestión (sonido producido, material utilizado en su fabricación, etc.), e incluso puede contribuir a diferenciar los instrumentos sucesores de los antecesores. Lo más sencillo es expresarlo mediante el vocablo antiguo, antepuesto al hiperónimo instrumento o al hiperónimo intermedio que corresponda si lo hubiere:

(90) Archilaúd. m. Antiguo instrumento musical de cuerda, parecido al laúd, pero de mayor tamaño y con el mástil más largo. 
(91) Bombarda. f. Antiguo instrumento musical de viento madera, parecido a la chirimía, con lengüeta doble de caña.

\subsection{Origen}

Se dará cuenta de este tipo de información fundamentalmente con los instrumentos que están ligados a una cultura determinada de manera muy clara. Es frecuente la existencia de instrumentos musicales de origen indígena, lo cual determina sin duda características relacionadas con $\mathrm{su}$ aspecto externo. Sintagmas preposicionales como de origen + gentilicio o simplemente adjetivos relacionales podrían ser sus vehículos de transmisión.

(92) Sistro. m. Antiguo instrumento musical de percusión de origen egipcio consistente en un aro o herradura de metal, atravesado por varillas, que se hacía sonar agitándolo.

(93) Teponastle. m. Instrumento musical indigena parecido al tambor, pero de menor tamaño.

(94) Ajabeba. f. Flauta morisca.

\subsection{Sonido resultante}

Puede especificarse este dato sobre todo si el sonido producido por el instrumento que se pretende definir puede calificarse de peculiar por uno u otro motivo (ejemplo 95). También si es un elemento distinguidor (ejemplo 96). En cualquiera de las dos situaciones, conviene utilizar las palabras sonido o tono en su codificación:

(95) Charrasca. f. Instrumento musical de percusión consistente en un cilindro provisto de ranuras que, al ser frotadas con una barra metálica o algo semejante, produce sonidos broncos.

(96) Bajoncillo. m. Instrumento musical de viento parecido al bajón, pero de menor tamaño y de tono más agudo.

\subsection{Tamaño}

En principio se utilizará este tipo de información si forma parte de una comparación que se atenga a las condiciones especificadas anteriormente (ejemplos 97 y 98), o si el tamaño es un elemento distinguidor en definiciones de formato hiperónimo intermedio + diferencia especifica (ejemplos 99 y 100). En el primero de los casos puede emplearse la construcción parecido a..., pero de menor/mayor tamaño, y en el segundo, el adjetivo grande o pequeño con modificador adverbial si fuera necesario:

(97) Viola. f. Instrumento musical de cuerda y arco, parecido al violín pero de mayor tamaño y sonido más grave.

(98) Ukelele. m. Instrumento musical de origen hawaiano, parecido a la guitarra pero de menor tamaño y con cuatro cuerdas.

(99) Armonio. m. Órgano pequeño, parecido al piano, al que se da aire por medio de un fuelle accionado con pedales.

(100) Bombo. m. Tambor muy grande que se toca con una maza. 


\subsection{Orden de aparición de los rasgos semánticos}

Por último, he de aludir a la necesidad de establecer un orden de aparición de los datos a los que me he referido hasta ahora. El que propongo es una posibilidad más (que ha sido aplicada en las definiciones propuestas en los subapartados anteriores), si bien ha de tenerse en cuenta que es importante seguirlo en la medida en que las definiciones no resulten artificiosas, y que estas no deben incluir todos los rasgos semánticos que se enumeran a continuación (ya han sido explicadas las condiciones que favorecen su inclusión o exclusión):

a) obsolescencia

b) familia (incluye el material en el caso de los instrumentos musicales de viento [instrumento musical de viento madera/metal], y el tamaño, en lo que se refiere a las definiciones del tipo hiperónimo intermedio + diferencia especifica [guitarra pequeña]).

c) origen

d) ámbito geográfico de uso

e) forma

f) comparación

g) elementos compositivos

h) modo de funcionamiento

i) sonido resultante

\section{CONCLUSIONES}

A lo largo de las páginas precedentes se ha insistido en la necesidad de confeccionar los diccionarios con coherencia y rigor metodológico, como fórmula para convertir estas obras en herramientas de consulta claras y precisas. En esta empresa es fundamental la elaboración de modelos definitorios, aplicables a grupos homogéneos de palabras, que reviertan en una mayor sistematicidad en las definiciones lexicográficas.

En el trabajo que aquí termina he expuesto un prototipo de definición destinado a los nombres de instrumentos musicales y que ha sido concebido para un diccionario de uso. En la elaboración del mismo he utilizado datos procedentes tanto de un corpus específico (el $C R E A$ ) como del resultado de comparar el tratamiento dado por algunos de los diccionarios más prestigiosos del español (en este caso el $D R A E$, el $D E A$ y el $D U E$ ) al citado conjunto de palabras. Es lo que he llamado método contrastivo, que, utilizado convenientemente, presenta numerosas ventajas en el proceso de descarte de los rasgos semánticos caracterizadores de determinado grupo de vocablos. En definitiva: se trata de un sistema de trabajo que ayuda a discernir los elementos informativa- 
mente necesarios de aquellos no relevantes en términos de delimitación lexicográfica. Fruto de su aplicación, se ha dado cuenta del tipo de datos que debe figurar en las definiciones de los nombres de instrumentos musicales en virtud de si se cumplen o no ciertos criterios. En cualquier caso, este no es un modelo cerrado, pero sí puede servir de punto de partida para avanzar en el complejo objetivo de la sistematización lexicográfica.

\section{REFERENCIAS BIBLIOGRÁFICAS}

AHUmada LARA, Ignacio (1989): Aspectos de lexicografia teórica, Granada, Universidad de Granada.

APRESJAN, Juri D. (2008): «Principles of Systematic Lexicography», en Thierry Fontenelle, ed., Practical lexicography, Oxford, Oxford University Press, pp. 51-60.

AtKins, B. T. Sue (2008): «Then and Now: Competence and Performance in 35 Years of Lexicography», en Thierry Fontenelle, ed., Practical Lexicography, Oxford, Oxford University Press, pp. 247-272.

BATIUKOVA, Olga (2009): «La teoría del léxico en los nuevos diccionarios», en Elena de Miguel, ed., Panorama de la lexicología, Barcelona, Ariel, pp. 487-519.

BÉJOINT, Henri y Philippe THOIRON (2002): «Schéma définitionnel, définition et traitement lexicografique des termes», Cahiers de lexicologie, 80, 1, pp. 121-134.

Benson, M.; Benson, E. y R. ILson (1986): Lexicographic Description of English, Amsterdam, John Benjamins.

CowIE, Anthony P. (2008): «Phraseology», en Thierry Fontenelle, ed., Practical lexicography, Oxford, Oxford University Press, pp. 163-167.

Church, Kenneth W. y Patrick Hanks (2008): «Word Association Norms, Mutual Information, and Lexicography», en Thierry Fontenelle, ed., Practical lexicography, Oxford, Oxford University Press, pp. 285-295.

DeCeSARIS, Janet Ann y Elisenda Bernal (2005): «La gramática de los nombres de materia en los diccionarios», en Juan Cuartero Otal y Gerd Wotjak, coords., Entre la semántica léxica, teoría del léxico y sintaxis, Frankfurt, Peter Lang, pp. 453-465.

De Miguel, Elena, Santiago U. SÁnchez JimÉnez, Ana Serradilla Castaño, RomanaAnca RADUleSCU y Olga BATIUKOVA, eds. (2009): Fronteras de un diccionario. Las palabras en movimiento, San Millán de la Cogolla, Cilengua. 
De Miguel, Elena, ed. (2009): Panorama de la lexicología, Barcelona, Ariel.

Del Moral, Rafael (2006): «Principios para un diccionario conceptual y sistemático de la lengua española», en Milka Villayandre Llamazares, ed., Actas del XXXV Simposio Internacional de la Sociedad Española de Lingüística, León, Universidad de León. También en http://www3.unileon.es/dp/dfh/SEL/actas.htm.

FILlmore, Charles J. (2008): “"Corpus Linguistics” or "Computer-aided Armchair Linguistics"», en Thierry Fontenelle, ed., Practical lexicography, Oxford, Oxford University Press, pp. 105-122.

GeERAERTS, Dirk (2003): «Meaning and definition», en Piet van Sterkenburg, ed., A Practical Guide to Lexicography, Amsterdam/Philadelphia, John Benjamins, pp. 83-93.

GONZÁlEZ COBAS, Jacinto (2009): «Los instrumentos de medida en el DRAE: una propuesta de modelo de definición», en Elena de Miguel, Santiago U. Sánchez Jiménez, Ana Serradilla Castaño, Romana-Anca Radulescu y Olga Batiukova, eds., Fronteras de un diccionario. Las palabras en movimiento, San Millán de la Cogolla, Cilengua, pp. 121147.

(2010): «Caracterización lingüística de los nombres de instrumentos musicales. Repercusiones lexicográficas», Revista de Lexicografia, XVI, pp. 39-58.

HANKS, Patrick (2008): «Do Words Meanings Exist?», en Thierry Fontenelle, ed., Practical lexicography, Oxford, Oxford University Press, pp. 125-134.

Kiefer, Ferenc y Piet Van Sterkenburg (2003): «Design and Production of Monolingual Dictionaries», en Piet van Sterkenburg, ed., A Practical Guide to Lexicography, Amsterdam/Philadelphia, John Benjamins, pp. 350-365.

KILGARRIFF, Adam (2008): «I Don’t Believe in Word Senses», en Thierry Fontenelle, ed., Practical Lexicography, Oxford, Oxford University Press, pp. 135-151.

—, Pavel RYChly, Pavel SMRŽ y David TUGWELl (2008): «The Sketch Engine», en Thierry Fontenelle, ed., Practical Lexicography, Oxford, Oxford University Press, pp. 297-306.

MOLINER, María $\left(2007^{3}\right)$ : Diccionario de uso del español, Madrid, Gredos.

Neubauer, F. (1987): «How to Define a Defining Vocabulary», en R. Ilson, ed., A Spectrum of Lexicography, Amsterdam, John Benjamins, pp. 49-59.

PASCUAL RodRíGUEZ, José Antonio (2003): «El comentario lexicográfico: tres largos paseos por el laberinto del diccionario», en Antonia María Medina Guerra, coord., Lexicografía española, Barcelona, Ariel, pp. 353-385. 
y Rafael GARCÍA PÉREZ (2007): Límites y horizontes en un diccionario histórico, Salamanca, Diputación de Salamanca.

PORTO DAPENA, José Álvaro (2007): «Una definición típica de los numerales: la de cálculo aritmético», Revista de lexicografía, XIII, pp. 105-124.

ReAl ACADEMia EsPañola (200122): Diccionario de la lengua española, Madrid, Espasa Calpe. También en http://www.rae.es.

: Banco de datos $(C R E A)$ [en línea]. Corpus de referencia del español actual. http://www.rae.es [marzo de 2011].

SÁNCHEZ JiMÉNEZ, Santiago U. (2010): «Construcción discursiva en el Libro de buen amor. Las palabras que designan instrumentos propios de la alimentación», en Nelly Labère, coord., Étre à table au Moyen Âge, Madrid, Casa de Velázquez, pp. 115-128.

SÁNCHEZ MARTín, Francisco Javier (2008): Estudio del léxico de la geometría aplicada a la técnica en el Renacimiento hispano, Tesis doctoral, Universidad de Salamanca.

SECO, Manuel; AndRÉS, Olimpia y Gabino RAMOs (1999 $)$ : Diccionario del español actual, Madrid, Aguilar.

SOLER I Bou, Joan (2003): Definició lexicogràfica i estructura del diccionari, Tesis doctoral, Universidad de Barcelona.

STOCK, Penelope F. (2008): «Polysemy», en Thierry Fontenelle, ed., Practical lexicography, Oxford, Oxford University Press, pp. 153-160.

Zgusta, L. (1971): Manual of Lexicography, The Hague, Mouton. 